

\section{ECO-LEGAL AND ECONOMIC ASPECTS OF DEVELOPING MALOMORSKY FISHING AREA OF LAKE BAIKAL}

Professor A.P. Sukhodolov - Head of the Laboratory of Interdisciplinary Ecological and Economic Research and Technologies, Limnological Institute of the Siberian Branch of the Russian Academy of Sciences;

A.P. Fedotov - Director, Limnological Institute SB RAS; Head of the Department of Aquatic Bioresources and Aquaculture, Baikal State University; M.M. Makarov - Senior Researcher, Laboratory of Interdisciplinary Ecological and Economic Research and Technologies,

Limnological Institute of SB RAS;

P. A. Anoshko - Staff Scientist, Laboratory of Interdisciplinary Ecological-Economic Research and Technologies, Limnological Institute SB RAS; A.V. Kolesnikova - expert on environmental legal expertise, Limnological Institute SB RAS;

Cand. Ekon. Sciences, associate Professor upland Ya.A. Sukhodolov - senior researcher, laboratory of TRANS-Baikal economic and international studies, economic research Institute Feb RAS;

P.G. Sorokina-Senior Lecturer, Department of Mathematics and Computer Science, Baikal State University; Junior Researcher, Laboratory of Interdisciplinary Ecological and Economic Research and Technologies, Limnological Institute of the Siberian Branch of the Russian Academy of Sciences.

3952_2015@mail.ru; mix@lin.irk.ru; mmmsoft@hlserver.lin.irk.ru; alinal2020@mail.ru; yakov.suhodolov@gmail.com; ermolaevapolina@mail.ru

Lake Baikal is the largest fresh water reservoir of our planet and a unique natural site included in the UNESCO World Heritage List. Meanwhile, Baikal is not only Russia's largest freshwater fishing reservoir. Large-scale commercial fishing started here at the beginning of the 19th century and, with small breaks caused by bans imposed on industrial fishing due to depletion of valuable commercial fishery species stock, continued until October 2017, when once again restrictions in the fishing industry were imposed. One of the reasons for this was the increasing of the illegal unreported and unregulated fishing which led to depletion of harvestable stock of omul. However, these restrictions neither eliminated extensive unreported fishing, nor solved the problem of rapid fish stock rebuilding in the unique lake. Using methods of mathematical analysis and modeling this article examines factors facilitating breach of law in the fishing industry and unreported fishing for Baikal omul. The article provides a brief characteristic of the Baikal oldest Malomorsky fishing area as well as an eco-economic assessment of the possibility to rebuild the fishing stock within this water zone taking into account the increasing tourist flow in the Baikal region.

\section{ВСТУПЛЕНИЕ}

Озеро Байкал - уникальное творение природы, величайшая национальная и мировая достопримечательность, включенная Комитетом по мировому наследию ЮНЕСКО в Список участков всемирного наследия (декабрь 1996 г.).

Особое место в уникальной фауне озера занимает байкальский омуль - эндемик Байкала и ценный промысловый вид рыбы. Существуют сказания и легенды об омуле и омулевой бочке Байкала. Литературные метафоры отражают отношение к омулю не только как к ценному продукту питания, деликатесу, но и как к своеобразному символу, бренду Байкала.

В пределах акватории Байкала выделяют несколько рыбопромысловых районов общей площадью 3150 тыс. га, где с середины XIX в. ведется масштабная рыбопромысловая деятельность, негативно отражающаяся на популяции омуля [3]. Задача восстановления его запасов впервые была поставлена в начале XX в. Вновь она стала актуальной после Великой Отечественной войны (в военные годы вылов омуля достигал максимальных величин, что истощило его популяцию), когда рекомендовали ограничить рыбный промысел на Байкале не менее чем на трехлетний период (начиная с 1945 г.), а также организовать обследование рыбопромысловых районов силами специалистов соответствующих рыбозаводов, запретить вылов неводами во время икрометания и обеспечить в нерестовый период свободное движение рыбы [1].

Позднее, к концу 1960-х гг., возникла необходимость в принятии уже экстренных мер по сохране- нию байкальского омуля, запасы которого вновь стали сокращаться в связи с превышением норм вылова в 2-3 раза [6]. Минрыбхоз СССР запретил на несколько лет вылов байкальского омуля ${ }^{1}$. Одновременно проводилась комплексная работа по повышению продуктивности рыбопромысловых акваторий Байкала, модернизации существующих и созданию новых рыборазводных предприятий. Именно в тот период построены Баргузинский, Бельский, Чивыркуйский и первая очередь Селенгинского завода по разведению рыбы, проведена реконструкция старейшего в бассейне Большереченского рыбозавода. Данные меры способствовали восстановлению омулевого стада на Байкале.

Недавно проблема сокращения запасов омуля вновь обострилась [8]. Его суммарная биомасса сократилась с 18-20 тыс. т в 2008 г. до 6,8-7,1 тыс. т в 2017-2018 гг. Очередной запрет промышленного вылова байкальского омуля и ограничение любительского и спортивного лова введены в августе 2017 г. ${ }^{2}$

Насколько эффективна современная запретительная политика в сфере рыболовства на Байкале? В результате ее реализации, одновременно с сокращением объема общедопустимого улова, стали снижаться показатели учтенного улова омуля. При этом увеличивается незаконный, несообщаемый и нерегулируемый вылов [14]. Применение одних только запретительных мер для рыбного промысла в пределах Байкальской природной территории (БПТ) порождает прогрессирующие процессы криминализации рассматриваемой

Приказ Минрыбхоза СССР «Об утверждении Правил рыболовства в бассейне озера Байкал и других рыбохозяйственных водоемах Бурятской АССР, Иркутской и Читинской областей» от 01.12.1969 г. № 401.

${ }^{2}$ Приказ Минсельхоза РФ от 29.08.2017 № 450 «О внесении изменений в правила рыболовства для Байкальского рыбохозяйственного бассейна, утвержденные приказом Министерства сельского хозяйства Российской Федерации от 7 ноября 2014 г. № 435». 
сферы [10]. Это выражается как в сокрытии уловов, так и предоставлении заведомо искаженной информации, что классифицируется как нарушение Правил рыболовства.

Согласно данным Росприроднадзора России, МВД по Республике Бурятия, ГУВД по Иркутской области и УМВД по Забайкальскому краю количество преступлений, предусмотренных ст. 256 УК РФ и совершенных на БПТ в период с 2012 по 2018 г., увеличилось на 45\% (табл. 1).

Тенденция к снижению количества зарегистрированных административных правонарушений при вылове байкальского омуля, обозначенная во втором столбце таблицы 1 , вряд ли связана с действенностью введенного запрета на его вылов, с учетом высокой степени латентности подобных правонарушений и ростом конфискованного, незаконно добытого омуля (после введения запрета на его вылов в октябре 2017 г.), которое увеличилось на 6,3 тонн.

\section{МАТЕРИАЛЫ И МЕТОДЫ}

Был проведен анализ криминогенных факторов, детерминирующих правонарушения и преступность в сфере рыболовства на Байкале, с использованием математического аппарата, а также построена непрерывная модель динамики численности омуля, с учётом незаконного вылова. Модельной территорией, для повышения эффективности рыбохозяйственной деятельности на территории БПТ, авторами предложен район Малого Моря, где с помощью гидроакустической съемки определялась емкость и оценивались перспективы зарыбления этого старейшего на Байкале промыслового района, с целью использования его рыбных ресурсов для развития туризма в этой части Байкала.

\section{ПОЛУЧЕННЫЕ РЕЗУЛЬТАТЫ}

На основе статистических данных за период 2004-2018 гг. предложена модель множественной регрессии $\mathrm{W}=-1944,03+73,51 \mathrm{x}_{3}+0,81 \mathrm{x}_{4}+0,32 \mathrm{x}_{5}$, отражающая зависимость количества административных нарушений в сфере вылова байкальского омуля $\mathrm{W}$ от уровня бедности $\mathrm{x}_{3}$, численности туристов $\mathrm{x}_{4}$ и общего допустимого улова омуля $\mathrm{x}_{5}$. Отметим, что данные факторы оказались наиболее значимыми, в соответствии с критерием Фишера, а модель является пригодной для
Озеро Байкал - крупнейший пресноводный водоем планеты и уникальный природный объект, занесенный ЮНЕСКО в Список объектов всемирного наследия. При этом Байкал - крупнейший пресноводный рыбохозяйственный водоем не только России. Масштабный рыбный промысел здесь начат в конце XIX в. и, с незначительными перерывами, вызванными запретами на промышленный лов, ввиду истощения запасов ценных промысловых видов рыбы, продолжался до октября 2017 г., когда в очередной раз были введены ограничительные меры в сфере рыболовства на Байкале. Одной из причин этого стал нарастающий незаконный, несообщаемый и нерегулируемый вылов, приведший к истощению промысловых запасов омуля. Однако ограничительные меры не исключили фактов браконьерства, носящих массовый характер, и не решили проблему скорейшего восстановления рыбных запасов уникального озера. В настоящей статье, при помощи методов математического анализа и моделирования, исследуются факторы, порождающие правонарушения в сфере рыболовства, обуславливающие незаконный вылов байкальского омуля. Дается краткая характеристика старейшего на Байкале Маломорского рыбопромыслового района и эколого-экономическая оценка возможности ускоренного восстановления рыбных ресурсов в пределах данной акватории, с учетом растущего потока туристов в Прибайкалье.

\section{использования с коэффициентом детерминации} $\mathrm{R}^{2}=0,7$.

С учетом криминогенной ситуации, связанной с браконьерской деятельностью на Байкале, авторами предложена следующая непрерывная модель динамики численности популяции омуля [11]:

$\dot{\mathrm{x}}=\mathrm{ax}+\mathrm{b}-\mathrm{cxu}-\mathrm{dxu}(1-\mathrm{u}), \mathrm{u} \in[0,1], \mathrm{x}\left(\mathrm{t}_{0}\right)=\mathrm{x}_{0}, \mathrm{t} \in\left[\mathrm{t}_{0}, \mathrm{t}_{1}\right]$.

Здесь $\mathrm{a}, \mathrm{b} \in \mathrm{R}$ - коэффициенты, характеризующие естественный прирост (убыль) популяции без учета вылова; $c \in \mathrm{R}_{+}-$коэффициент эффективности вылова игрока $\mathrm{A}$, занимающегося официальным промыслом; $\mathrm{d} \in \mathrm{R}_{+}$- коэффициент эффективности вылова игрока В (нелегальных добытчиков), который, ориентируясь на интенсивность вылова игрока А, также принимает участие в вы-

Таблица 1. Динамика правонарушений в сфере рыболовства на БПТ в 2012-2018 годах [11] /

Table 1. Dynamics of offenses in the field of fishing on the BPT in 2012-2018 [11]

\begin{tabular}{ccc}
\hline Год & Количество зафиксированных преступлений & $\begin{array}{c}\text { Количество протоколов об административных } \\
\text { правонарушениях }\end{array}$ \\
\hline 2012 & 187 & 3471 \\
2013 & 150 & 3389 \\
2014 & 191 & 2864 \\
2015 & 149 & 3110 \\
\hline 2016 & 129 & 3629 \\
\hline 2017 & 235 & 2510 \\
\hline 2018 & 333 & 2012 \\
\hline
\end{tabular}


Таблица 2. Динамика туристического потока на Байкал (в пределах Иркутской области) в 2016-2018 годах* / Table 2. Dynamics of tourist flow to Lake Baikal (within the Irkutsk region) in 2016-2018*

\begin{tabular}{ccccc}
\hline Показатель & $\mathbf{2 0 1 6}$ & $\mathbf{2 0 1 7}$ & $\mathbf{2 0 1 8}$ & Изменение, \% \\
\hline Количество туристов, тыс. чел. & 1526 & 1598 & 1656 & +16 \\
\hline В том числе иностранных & 157 & 211 & 295 & +88 \\
$\begin{array}{c}\text { Объем платных услуг в сфере } \\
\text { туризма, млн руб. }\end{array}$ & 5371 & 5601 & 6238 & +16 \\
\hline
\end{tabular}

* расчеты авторов

Таблица 3. Динамика развития туризма в районе Малого Моря в 2016-2018 годах* /

Table 3. Dynamics of tourism development in the Maly Sea region in 2016-2018*

\begin{tabular}{|c|c|c|c|c|}
\hline Показатель & 2016 & 2017 & 2018 & Изменение, \% \\
\hline $\begin{array}{c}\text { Количество прибывших на о. Ольхон туристов, } \\
\text { тыс. чел. }\end{array}$ & 110 & 273 & 530 & +382 \\
\hline $\begin{array}{c}\text { Доля туристов, посещающих Малое Море, в общем } \\
\text { потоке прибывших в Иркутскую область, \% }\end{array}$ & 7,2 & 17,1 & 32,0 & +344 \\
\hline $\begin{array}{c}\text { Количество доставленных паромом на о. Ольхон } \\
\text { автомобилей, тыс. }\end{array}$ & 30,4 & 71,3 & $\ldots$ & +134 \\
\hline Количество коллективных средств размещения ${ }^{4}$ & 89 & 97 & 104 & +17 \\
\hline Оборот в общественном питании, млн руб. & 24,8 & 26,4 & 27,8 & +12 \\
\hline Оборот в розничной торговле, млн руб. & 759,2 & 796,8 & 860,8 & +13 \\
\hline
\end{tabular}

*данные администрации Ольхонского муниципального образования

лове; $\mathrm{x}_{0}$ - численность популяции в начальный момент времени $\mathrm{t}_{0}$; схи - «мгновенный» вылов игрока A; $\operatorname{dxu}(1-u)$ - «мгновенный» вылов игрока $\mathrm{B}$; временной промежуток $\left[\mathrm{t}_{0}, \mathrm{t}_{1}\right]$ фиксирован. Фазовая переменная $\mathrm{x}(\mathrm{t})$ означает численность популяции омуля в момент времени $\mathrm{t}$, а управляющая переменная ut - интенсивность отлова «официальным» игроком А в момент времени t.

В рамках представленной модели, с учетом незаконного вылова, можно рассмотреть некоторые задачи оптимального управления с интегральным целевым функционалом (и, возможно, ограничениями), описывающие различные цели со стороны как «официального» добытчика, так и браконьеров. Для их исследования можно применять классический принцип максимума Понтрягина, а также позиционный принцип минимума [15], развиваемый иркутской школой оптимального управления.

Показательным для отработки мер по повышению эффективности рыбохозяйственной деятельности на БПТ, с учетом растущей туристической привлекательности Байкала, является район его Малого Моря, которое расположено между западным побережьем и самым крупным островом Ольхоном.

Протяженность Малого Моря 76 км, ширина от 17 км (максимальная) до 4 км (минимальная),


Именно здесь расположен старейший Маломорский рыбопромысловый район - исторический центр добычи омуля на Байкале. Омулевое стадо представлено так называемой селенгинской популяцией, с размерами крупных рыб до 50 см и массой до 5,0 кг, при средней массе промыслового омуля порядка 350 г. [2].

На прибрежной территории Малого Моря, отнесенной к центральной зоне БПТ, ограничена хозяйственная деятельность, за исключением туризма, рыбного промысла, сельского хозяйства и торговли. При этом рыбный промысел представляет собой старейшую отрасль специализации данной территории, развитие которой получает новый импульс в связи с растущей популярностью у туристов этого района Байкала.

Росту туристского потока на Малое Море способствует ряд факторов. Живописные горно-таежные и степные ландшафты. Самое большое на побережье Байкала количество солнечных дней в году, где продолжительность солнечного сияния более 2200 часов в год (о. Ольхон), что превышает аналогичный показатель на Рижском взморье (1840 часов) и Кисловодске (около 2000 часов). Вдоль побережья много удобных для отдыха и стоянок бухт и мелководных заливов, где летом вода прогревается до $+20^{\circ} \mathrm{C}$, что делает их привлекательными и популярными у отдыхающих. В их числе залив Мухор, побережье которого застроено множеством баз отдыха ${ }^{3}$. Немаловажен и фактор доступности. Район связан с Иркутском автобусным и водным сообщением, а с о. Ольхон - паромной переправой. Планируется также возобновить авиасообщение между Иркутском и о. Ольхон (пос. Харанцы), прерванное в 1990-

${ }^{3}$ Министерство природных ресурсов и экологии РФ. (2019). О состоянии озера Байкал и мерах по его охране в 2018 году. Иркутск, Российская Федерация, АНО «КЦ Эксперт».

${ }^{4}$ Средства размещения туристов располагаются главным образом вдоль побережья Малого Моря, в том числе на о. Ольхон, на территории Хужирского и Шара-Тогодского муниципальных образований. 
х гг., что повысит туристскую привлекательность района. Все эти факторы способствуют развитию индустрии туризма в этой части Байкала и росту туристского потока на Байкал (табл. 2), а также в район его Малого Моря (табл. 3) [7, 9, 12].

Растущая туристическая привлекательность района положительно сказывается на развитии смежных отраслей, в том числе рыбного хозяйства, поскольку растут закупки рыбной продукции со стороны многочисленных туристских баз, к тому же туристы приобретают байкальский омуль и вывозят его за пределы региона в качестве экзотического подарка с берегов Байкала.

Для развития рыбной отрасли в этой части Байкала также имеются необходимые эколого-экономические и исторические предпосылки. Достаточно сказать, что наличие высокопродуктивной сырьевой базы и имеющиеся на данной территории трудовые ресурсы обусловили размещение в 1938 г. в центральной части о. Ольхон (в пос. Хужир) Маломорского рыбозавода. На заводе действовали мощные холодильные установки для быстрой заморозки рыбы, крупные цехи по засолке и копчению, позволявшие перерабатывать более 2 т рыбы в сутки, имелось консервное производство (табл. 4) [13].

\section{ОЦЕНКА ПОТРЕБНОСТИ В ОМУЛЕ} МЕСТНОГО НАСЕЛЕНИЯ И ТУРИСТОВ

Население Ольхонского района Иркутской области, в пределах которого располагается Малое Mope, традиционно потребляло байкальский омуль в качестве важного продукта питания. По состоянию на 2019 г. в районе проживало 9,5 тыс. человек. При нормах потребления, установленных Приказом Минздрава России для здорового питания от 19 августа 2016 г. № 6145 , на взрослого человека в год требуется 22 кг рыбопродуктов. Потребность в омуле всех жителей района можно приблизительно оценить в 105 т (11 кг в год на человека), при условии поставок в район морской рыбопродукции и с учетом половозрастной структуры населения (дети, старики).

Оценивая потребность в омуле посещающих Малое Море туристов, необходимо учесть два важных фактора. Во-первых, динамику роста турпотока, который за 2016-2018 гг. вырос 3,8 раза - до
530 тыс., при одновременном росте доли посещающих Малое Море с 7,2 до 32,0\% (табл. 3). Второй фактор - это многолетние данные туроператоров о пищевых предпочтениях туристов на Байкале, предпочитающих не завезенную морепродукцию, а местную, прежде всего, байкальский омуль, среднее потребление которого одним туристом оценивается в 100-150 г в сутки. Таким образом, общую потребность в омуле, при среднем пребывании туристов на Малом Море 2,5 сут. и среднем турпотоке в 500 тыс. чел., можно оценить в 125 т. С увеличением числа туристов эта потребность может возрасти до 200 тонн.

Здесь же следует учесть потребность в омуле обслуживающего персонала туристических баз и мест размещения отдыхающих (в 2018 г. 104 ед.), которая оценивается примерно в 0,71,2 т за сезон.

Таким образом, современную и перспективную общую потребность в омуле местного населения, обслуживающего персонала и туристов в данном районе можно оценить в 230-305 т, что сопоставимо с предельной естественной рыбопродуктивностью всего Маломорского рыбопромыслового района. В этой связи возникает идея создания в районе Малого Моря мощностей по искусственному рыборазведению. Но насколько они будут продуктивны?

ЭКОЛОГО-ЭКОНОМИЧЕСКАЯ ОЦЕНКА
ЦЕЛЕСООБРАЗНОСТИ СОЗДАНИЯ ПРЕДПРИ-
ЯТИЯ ПО РЫБОРАЗВЕДЕНИЮ НА МАЛОМ МОРЕ
Идея создания в районе Малого Моря рыбо-
водного завода стала активно обсуждаться по-
сле запрета на промышленную добычу омуля
на Байкале в 2017 г. Министерство сельского
хозяйства Иркутской области подготовило ры-
боводно-биологические обоснования по стро-
ительству подобного предприятия в д. Сарма с
включением основных мероприятий в ФЦП «Ох-
рана озера Байкал и социально-экономическое
развитие Байкальской природной территории
на 2012-2020 годы». По мнению авторов идеи,
завод должен был компенсировать ущерб от не-
законного вылова на Малом Море сарминского
придонно-глубоководного омуля, а также чер-
ного байкальского хариуса и озерного сига. Как
сообщала пресс-служба губернатора Иркутской

Таблица 4. Динамика выпуска продукции Маломорским рыбозаводом в 1995-2000 годы, т [13] / Table 4. Dynamics of output by the Malomorsky fish factory in 1995-2000, t [13]

\begin{tabular}{ccccccc}
\hline $\begin{array}{c}\text { Вид омулевой } \\
\text { продукции }\end{array}$ & $\mathbf{1 9 9 5}$ & $\mathbf{1 9 9 6}$ & $\mathbf{1 9 9 7}$ & $\mathbf{1 9 9 8}$ & $\mathbf{1 9 9 9}$ & $\mathbf{2 0 0 0}$ \\
\hline Свежемороженый & 21,8 & 51,4 & 72,5 & 117,7 & 292,1 & 262,6 \\
$\begin{array}{c}\text { Слабосоленый } \\
\text { Холодного }\end{array}$ & 462,0 & 289,4 & 133,4 & 144,5 & 41,1 & 65,8 \\
копчения & 68,8 & 9,0 & 24,8 & - & - & 5,6 \\
Всего & $\mathbf{5 5 2 , 6}$ & $\mathbf{3 4 9 , 8}$ & $\mathbf{2 1 4 , 9}$ & $\mathbf{2 6 2 , 2}$ & $\mathbf{3 3 3 , 2}$ & $\mathbf{3 3 4 , 0}$ \\
\hline
\end{tabular}

${ }^{5}$ Министерство здравоохранения РФ. (2016). Об утверждении рекомендаций по рациональным нормам потребления пищевых продуктов, отвечающих современным требованиям здорового питания. (19.08.2016 г. № 614). URL: http://consultant.ru/document/cons_doc_LAW_204200.

${ }^{6}$ Правительство РФ (2012). О федеральной целевой программе «Охрана озера Байкал и социально-экономическое развитие Байкальской природной территории на 2012-2020 годы. (21 авг. 2012 г. № 847) URL: http://consultant.ru/document/cons_doc_LAW_134427. 
Таблица 5. Примерные затраты на покупку и доставку мальков* /

Table 5. Approximate costs for the purchase and delivery of fry*

\begin{tabular}{|c|c|c|c|c|}
\hline \multirow[b]{2}{*}{ Рыбозавод } & \multicolumn{2}{|c|}{ Стоимость } & \multirow{2}{*}{$\begin{array}{c}\text { Стоимость } \\
\text { доставки, р. за } 1 \text { км }\end{array}$} & \multirow{2}{*}{$\begin{array}{c}\text { Итоговая стоимость } \\
\text { (покупка + доставка), } \\
\text { тыс. р. }\end{array}$} \\
\hline & одного малька, p. & $\begin{array}{l}110 \text { млн мальков, } \\
\text { млн р. }\end{array}$ & & \\
\hline $\begin{array}{c}\text { Бельский (Иркутская } \\
\text { область) }\end{array}$ & 15,0 & 1650 & & 1650844 \\
\hline $\begin{array}{c}\text { Селенгинский } \\
\text { (Республика Бурятия) }\end{array}$ & 12,2 & 1342 & 200,0 & 1343529 \\
\hline
\end{tabular}

* расчеты авторов

области, данную идею губернатор С. Левченко обсуждал в 2019 г. с министром природных ресурсов и экологии России Д. Кобылкиным ${ }^{7}$ В этот же период подобная идея, но со строительством завода в Северобайкальске и также с включением в ФЦП, предлагалась правительством Республики Бурятии. Сколько рыбоводных заводов должно быть на Байкале? Насколько они эффективны?

Отметим, что на Байкале в советское время построили пять подобных заводов: в Бурятии (Большереченский, Селенгинский, Баргузинский и Чивыркуйский) и в Иркутской области (Сарминский). Кроме того, в акватории Иркутского водохранилища был построен Бурдугузский завод, но он не занимался разведением омуля для Байкала. К настоящему времени по социально-экономическим и технологическим соображениям были закрыты Сарминский и Чивыркуйский заводы, из-за низкой эффективности на грани закрытия оказался Баргузинский рыбоводный завод, не вошедший ни в одну программу по реконструкции. Возникает вопрос, целесообразно ли в этих условиях строительство подобного завода на Малом Море и есть ли этому альтернатива?

В настоящее время в Иркутской области искусственным воспроизводством рыбных ресурсов занимаются Бельский и Бурдугузский рыбоводные заводы, которые имеют мощности по разведению соответственно 10,6 и 0,2 млн мальков омуля в год. Но эти заводы не выпускают молодь в оз. Байкал. По нашим оценкам, приобретение только на Бельском заводе мальков омуля и их транспортировка на Малое Море (почти 400 км) потребует значительных затрат (табл. 5). При этом оба завода смогут обеспечить не более 11 млн мальков в год (при емкости Малого Моря в 110 млн мальков в год), что в 10 раз меньше потребности.

Меньше затрат будет при покупке мальков в Республике Бурятия. Однако здесь тоже нет достаточных мощностей для полного обеспечения приемной емкости Малого Моря, а мальков до Малого Моря придется также транспортировать автотранспортом на еще большее расстояние (695 км), с Селенгинского экспериментального рыбоводного завода (филиал «НПЦ рыбного хозяйства «Востсиб»).

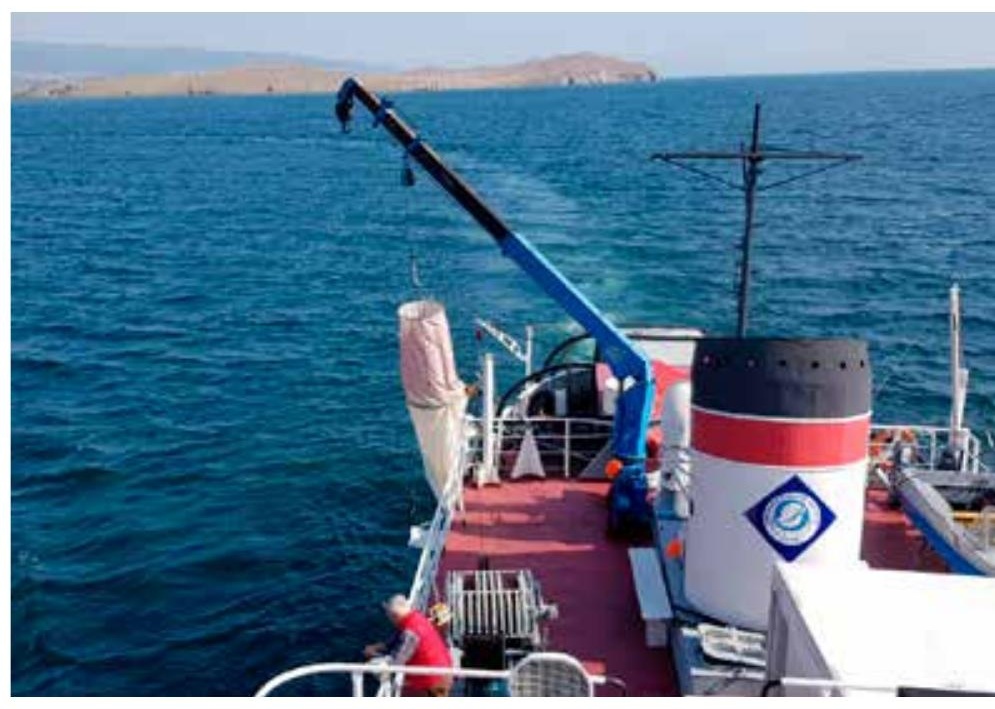

ЗАКЛЮЧЕНИЕ

Статистика свидетельствует, что объемы промышленного вылова омуля в Малом Море в последние годы колебались в пределах 100-350 т в год (330-1200 тыс. шт.). Акустическая съемка акватории Малого Моря, проведенная в 2007 г. оценила количество промыслового омуля в акватории в 2 млн шт. [5]. Эти данные убедительно показывают, что естественная биологическая емкость Малого Моря не способна обеспечить растущие потребности туристской индустрии данного района Байкала в омуле. Более того, с бурным развитием туризма в данном районе Байкала будет нарастать нагрузка на естественную экосистему и биоресурсы Малого Моря, сдерживать естественное воспроизводство данного вида рыбы с угрозой истощения его запасов.

Завоз мальков омуля в акваторию Малого Моря сразу с нескольких рыборазводных заводов БПТ, для обеспечения их ежегодного выпуска в требуемом количестве (110 млн), представляется невозможным. Это связано также и с тем, что лишь незначительная доля выпущенных в озеро мальков доживает до 4-5-летнего возраста.

Рыбоводный завод на Малом Море тоже представляется малоэффективным, как с экономической, так и с экологической точки зрения. Его строительство предусматривалось Программой комплексного социально-экономического развития Ольхонского района на 2014-2016 гг. с выде- 
лением прибрежной территории вблизи д. Сарма площадью 28 га. Основным инвестором выступало ООО «Байкальская рыба». Нормативные сроки строительства - 5-6 лет, объем инвестиций - 120 млн р., численность рабочих - 25 человек. Текущее содержание завода оценивалось в 15-18 млн р. Однако данный инвестпроект так и не был реализован.

В этой связи становятся актуальными комплексные и междисциплинарные эколого-экономические исследования, оценивающие эффективность искусственного зарыбления на Байкале, а также целесообразность строительства рыбоводных заводов вообще и в пределах акватории Малого Моря, в частности.

Работа выполнена при поддержке Министерства науки и высшего образования Российской Федерации, проект «Эколого-экономическая оценка функционирования пресноводных биогеоцинозов, фундаментальные и прикладные аспекты», $N^{o}$ гос. регистрации АAАA-A19-119070190033-0, № МИНОБРНАУКИ 0279-2019-0003.

\section{ЛИТЕРАТУРА И ИСТОЧНИКИ}

1. Аргунова Ю.Ю. История рыбного хозяйства Байкальского региона1900-1980 гг.: диссертация .... кандидата исторических наук 07.00.02. - Иркутск, 2016. - 250 с.

1. Argunova Yu. Yu. History of fisheries of the Baikal region1900-1980: dissertation ... Candidate of Historical Sciences 07.00.02. - Irkutsk, 2016. - 250 p.

2. Базов А.В., Базова Н.В. Селенгинское население Байкал-Омуля: прошлое, настоящее, будущее. / А.В. Базов, Н.В. Базова - Бурятский научный центр СО РАН, 2016. - 352 с.

2. Bazov A.V., Basova N. V. Selenginsky population of Baikal-Omul: past, present, future. /A.V. Bazov, N. V. Basova-Buryat Scientific Center SB RAS, 2016. - 352 p.

3. Дегтярев В.А. Распространение омуля (Coregonus Autumnalis Migratorius) в разных районах Байкала по акустическим данным / В.А. Дегтярев, П.П. Шерстянкин, Н.Г. Мельник - №152. // Известия Тихоокеанского научно-исследовательского рыбохозяйственного центра, 2008. - С. 58-63.

3. Degtyarev V. A. Distribution of omul (Coregonus Autumnalis Migratorius) in different areas of lake Baikal on acoustic data. / V. A. Degtyarev, p. P. Sherstyankin, N. G. Miller - No. 152. // Proceedings of scientific-research fisheries center Pacific, 2008. - P. 58-63.

4. Кожов М., Мишарин К. (1943). Биология рыб и рыбный промысел в Малом Море. / М. Кожов, К. Мишарин - Иркутск: Иркутское областное издательство, 1943. - 51 с.

4. Kozhov M., Misharin, K. (1943). Biology of fish and fishing in the Small Sea. / M. Kozhov, K. Misharin-Irkutsk: Irkutsk Regional Publishing House, 1943. - 51 p.

5. Кудрявцев В.И., Дзюба Е.В. Гидроакустический учет ресурсов байкальского омуля. Справочники и определители по флоре и фауне озера Байкал. / В.И. Кудрявцев, Е.В. Дзюба - Новосибирск, Наука, 2009. - 243 c.

5. Kudryavtsev V. I., Dzyuba E. V. Hydroacoustic accounting of Baikal omul resources. Reference books and determinants on the flora and fauna of Lake Baikal. / V. I. Kudryavtsev, E. V. Dzyuba-Novosibirsk, Nauka, 2009. - 243 p.

6. Мамонтов А.М. Оценка общего улова омуля в озере Байкал / А.М. Мамонтов / / География и природные ресурсы. - 2009. - №1. - C. $5-80$.

6. Mamontov A.M. Assessment of the total catch of omul in Lake Baikal. // Geography and natural resources. - 2009. - No. 1. - pp. 5-80.

7. Потапова Е.В. Гармонизация рекреационных возможностей и растущего туристического потока на Байкальской природной территории / Е.В. Потапова, Я.А. Суходолов // Известия Бай- кальского Государственного Университета. - 2019. - Т. 29, №1. - C 7-17.

7. Potapova E. V. Harmonization of recreational opportunities and growing tourist flow in the Baikal natural territory. / E. V. Potapova, Ya. A. Sukhodolov // Izvestiya Baikalskogo Gosudarstvennogo Universiteta. - 2019. - Vol. 29, No. 1. - From 7-17.

8. Смирнов В.В. О мерах по сохранению ресурсов байкальского омуля Coregonus Migratorius / В.В. Смирнов, Н.С. Смирнова-Залуми, Л.В. Суханова, А.И. Благодетелев // Бюллетень науки о рыболовстве. - 2015. - Т. 4, № 8. - С. 42-48.

8. Smirnov.V. V. Smirnov, N. S. Smirnova-Zalumi, L. V. Sukhanova, A. I. Blagodetelev On measures to preserve the resources of the Baikal Whitefish omul Migratorius. - 2015. - Vol. 4, No. 8. - pp. 42-48.

9. Суходолов А.П. Байкальский регион как модельная территория устойчивого развития // Известия Иркутской государственной экономической академии. - 2010. - № 4. - С. 103-108.

9. Sukhodolov A. P. Baikal region as a model territory of sustainable development. // Proceedings of the Irkutsk State Academy of Economics, 2010, no. 4, pp. 103-108.

10. Суходолов А.П. Математическое моделирование в исследовании комплекса детерминантов незаконного вылова водных биоресурсов (омуля) в озере Байкал / А.П. Суходолов, А.П. Федотов, П.Н. Аношко, А.В. Колесникова, П.Г. Сорокина Н.В. Мамонова // Всероссийский Криминологический Журнал - 2020. - № 14. - С. 76-86.

10. Sukhodolov A. P. Mathematical modeling in the study of the complex of determinants of illegal fishing of aquatic bioresources (omul) in Lake Baikal. / A. P. Sukhodolov, A. P. Fedotov, P. N. Anoshko, A.V. Kolesnikova, P. G. Sorokina N. V. Mamonova // All Russian Criminological Journal - 2020. - No. 14. - pp. 76-86.

11. Суходолов А.П. Математическое моделирование оценки численности байкальского омуля в системе социально-экономических и правовых аспектов экологической правонарушаемости / А.П. Суходолов, А.П. Федотов, М.М. Макаров, П.Н. Аношко, Е.В. Губай, В.И. Зоркальцев, А.В. Лебедева // Всероссийский Криминологический Журнал. - 2019. - № 13. - С. 757-771.

11. Sukhodolov A. P. Mathematical modeling of the Baikal omul population estimation in the system of socio-economic and legal aspects of environmental delinquency. / A. P. Sukhodolov, A. P. Fedotov, M. M. Makarov, P. N. Anoshko, E. V. Gubay, V. I. Zorkaltsev, A.V. Lebedeva // All - Russian Criminological Journal. - 2019. - No. 13. - pp. 757-771.

12. Суходолов А.П. Перспективы российско-монгольского сотрудничества в сфере международного туризма в Байкальском регионе (на примере туристического маршрута Байкал-Хубсугул) / А.П. Суходолов, В.В. Бережных // Baikal Research Journal. - 2011. - № 2. - C. 46-46.

12. A Sukhodolov.P. the prospects of Russian-Mongolian cooperation in the sphere of international tourism in Baikal region (on the example of the tourist route, the Baikal-Khubsugul). / A. P. upland Vladimir Berezhnykh // Baikal-Research Journal. - 2011. - No. 2. Pp. 46-46.

13. Суходолов А.П. Развитие рыбной промышленности Иркутской области / А.П. Суходолов, С.И. Виолин, О.В. Тетерина // Известия Иркутской Государственной Экономической Академии. - 2003. - № 2 (35). - C. 6-12.

13. Upland A. P. the Development of the fishing industry of the Irkutsk region. / A. P. upland, S. I. Violin, and O. V. Teterina / / Proceedings of the Irkutsk State Economic Academy. - 2003. - № 2 (35). - Pp. 6-12. 14. Тулохонов А.К. О причинах и следствиях новых природоохранных ограничений на байкальской природной территории // Известия русского географического общества. - 2018. - Т. 150, № 5. - C. 48-55.

14. Tulokhonov A. K. On the causes and consequences of new environmental restrictions on the Baikal natural territory. // Izvestiya Russian Geographical Society. - 2018. - Vol. 150, No. 5. - pp. 48-55.

15. Dykhta, V., Sorokin, S. (2019). Feedback minimum principle for optimal control problems in discrete-time systems and its applications. Lecture Notes in Computer Science, vol. 11548, pp. 449-460.

15. Dykhta V., Sorokin S. (2019). The principle of minimum feedback for optimal control problems in discrete-time systems and its applications. Lecture Notes on Computer Science, volume 11548, pp. 449-460. 